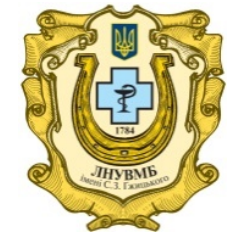

Ukrainian Journal of

Veterinary and Agricultural Sciences

http://ujvas.com.ua

Stepan Gzhytskyi National University of Veterinary Medicine and Biotechnologies Lviv

original article $\mid \quad$ UDC 636.034:619:612.018.2 | doi: 10.32718/ujvas1-2.05

Volume 1

Number 2

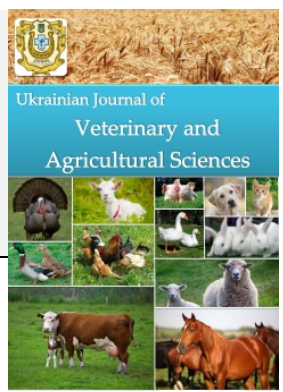

\title{
The role of insulin-like growth factor and leptin in the pathogenesis of internal non-contagious pathology of dairy cows
}

\author{
I. Petruh ${ }^{1}$, M. Simonov ${ }^{2}$, V. Vlizlo ${ }^{1,2}$, D. Ostapiv ${ }^{1}$ \\ ${ }^{1}$ Institute of animal biology NAAS, V. Stusa Str., 38, Lviv, 79034, Ukraine \\ ${ }^{2}$ Stepan Gzhytskyi National University of Veterinary Medicine and Biotechnologies Lviv, Pekarska Str., 50, Lviv, 79010, Ukraine
}

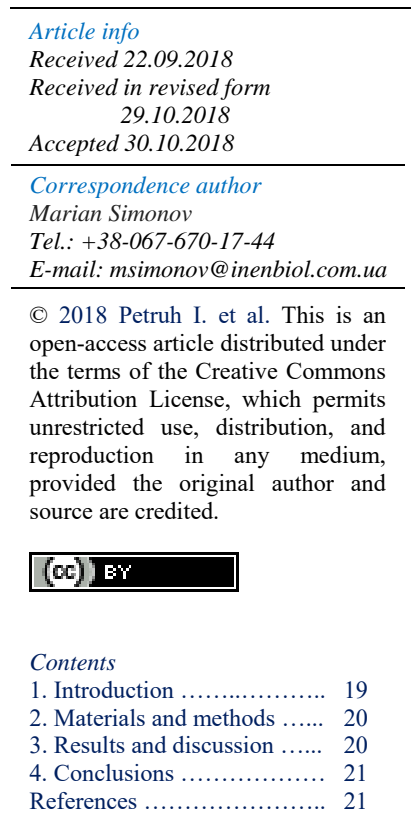

\begin{abstract}
The endocrine system plays a key role in the pathogenesis of the non-infectious pathology of dairy cows. However, the role of a number of hormones in pathology is not clear. These hormones include insulin-like growth factors and leptin. The insulin-like growth factor is synthesized predominantly in the liver in response to an increase in the level of somatotropic hormone in the blood. According to its physiological properties, it is close to insulin, structurally similar, has common receptors that trigger the same chain of reactions: stimulates transport of amino acids and glucose in the muscles, increases the sensitivity of cells to insulin, in adipose tissue, transport glucose, oxidation of glucose to carbon dioxide, the inclusion of glucose in lipids. Leptin is synthesized by adipocytes, and its main physiological function is to reduce the synthesis of macroergic compounds and increase energy expenditure. Circulating in the blood, it helps to maintain an optimal level of glucose, which is necessary for the energy needs of the body. The purpose of this study was to investigate the concentration of insulin-like growth factor, leptin, glucose, pyruvate and lactate in the blood of cows under secondary osteodystrophy, ketosis and hepatodistrophy. This will give an opportunity to better understand the pathogenesis and create theoretical preconditions for the development of informative diagnostic tests and effective means of treatment. The experiment was conducted on dairy cows, analogues by age, breed, productivity and physiological state. According to clinical features, urine analysis and values of biochemical parameters of blood of experimental cows were divided into four groups: 1 - clinically healthy cows, 2 - patients with osteodystrophy, 3 - patients with ketosis, 4 - patients with hepatodistrophy. The obtained results of research indicate that the internal non-contagious pathology in dairy cows deficiency of exchange energy is recorded, which induces an increase in the activity of gluconeogenesis and is expressed by lowering the concentration of glucose and increasing the content of pyruvate and lactate. At the same time, a decrease in the level of insulin-like growth factor and leptin was found. The lowest level of insulin-like growth factor and leptin was determined by ketosis. The decrease in the level of tissue hormones in the blood plasma of cows under osteodystrophy was within the statistical error.
\end{abstract}

Key words: cows, hepato-dystrophy, ketosis, osteodystrophy, insulin-like growth factor, leptin.

\section{Citation:}

Petruh, I., Simonov, M., Vlizlo, V., \& Ostapiv, D. (2018). The role of insulin-like growth factor and leptin in the pathogenesis of internal non-contagious pathology of dairy cows. Ukrainian Journal of Veterinary and Agricultural Sciences, 1(2), $19-22$.

\section{Introduction}

The dominant place in the structure of diseases of dairy cows is metabolic diseases (Levchenko et al., 2015). They are characterized by complex etiology and pathogenesis. The key role in pathogenesis of internal non-pathological pathology is endocrine system. Unfused hormones include insulin-like growth factor (IGF) and leptin. The IFI is synthesized predominantly in the liver in response to an increase in the level of somatotropic hormone in the blood. By its physiological properties, it is close to insulin, structurally similar, has common receptors that trigger the same chain of reactions: stimulates transport of amino acids and glucose in the muscles, increases the sensitivity of cells to insulin, in the adipose tissue - transport glucose, oxidation of glucose to $\mathrm{CO} 2$, inclusion glucose in lipids (Kim, 2014; Vlizlo \& Simonov, 2017). Low levels of IFI-1 are associated with hepatic insufficiency, intestinal inflammation, renal insufficiency (Nikolic-Judith et al., 2001). Correlation between hydrocarbon, lipid, protein metabolism and IGF-1 synthesis was established (Nikolic-Judith et al., 2001; Partridge et al., 2011).

Another less-known tissue hormone is leptin. Leptin is synthesized with adipocytes, and its main physiological function is to reduce the synthesis of macroergic compounds and increase energy expenditure. By circulating in the blood, it helps to maintain an optimal level of glucose, which is necessary for the energy needs of the body (Montague et al., 1997).

The aim of the research was to study the concentration of IFI, leptin, glucose, pyruvate and lactate in the blood of cows for metabolic diseases, which will enable to better understand the pathogenesis and create theoretical precondi- 
tions for the development of informative diagnostic tests and effective means of treatment.

\section{Materials and methods}

The experiment was conducted on dairy cows (blackand-white Ukrainian dairy breed), which were analogues for live weight (480-550 kg), productivity (over $5000 \mathrm{~kg}$ per lactation) and physiological state (2-4 weeks after calving). Cows were examined clinically, and then blood and urine samples were taken. In selected urine samples, the ketone bodies (using Ketophan test strips) were determined by express diagnosis. Blood from animals was taken from the jugular vein before the morning feeding. Blood samples were taken from sterile test tubes with heparin and plasma was immediately centrifuged at $3.000 \mathrm{rpm}$. In selected samples of blood plasma by the method of immunoassay analysis (DRG test systems) on the analyzer Stat Fax 2200, the concentration of IFI and leptin was determined. The content of pyruvate was investigated in whole blood by a modified Umbratian method, lactate by reaction with paraoxydiphenyl, glucose by glucose oxidase method (Vlizlo et al., 2012).

Sampling was taken taking into account the "General Ethical Principles of Animal Experiments" (Ukraine, 2001) and in accordance with the provisions of the "European Convention for the Protection of Vertebrate Animals Used for Experimental and Other Purposes" (Strasbourg, 1985).

According to clinical features, urine analysis and values of biochemical parameters of blood of experimental cows were divided into four groups: 1 - clinically healthy cows (n $=7), 2$ - patients with osteodystrophy $(\mathrm{n}=4), 3$ - patients with ketosis $(\mathrm{n}=4), 4$ - patients with hepatodistrophy $(n=4)$.
The group of cows with osteodystrophy consisted of animals in which, during the clinical examination, demineralization of the caudal vertebrae, incorrect regulation of the limbs and lameness were established. The animals were depressed, little moved, some were observed Allotriophagia.

According to the results of a clinical study (odor of acetone from the skin and exhaled air) and an express diagnosis of ketone body contents in the urine of the cows, patients with clinically significant ketosis were found.

In the clinical study of cows suffering from hepatodistrophy, oppression, low mobility, loss of appetite, jaundice of the mucous membranes, palpation of pain in the liver, and percussion - an increase in the limits of the hepatic field are established.

The obtained data was processed on the computer in the Excel program, determining the average arithmetic value (M), the statistical error of the arithmetic mean value (m), the probability of the difference between the arithmetic mean of the two variation series $(\mathrm{P}<)$.

\section{Results and discussion}

The main indicator of carbohydrate metabolism is the concentration of glucose in the blood. As it is evident from the presented results of studies (Fig. 1), hypoglycemia have been diagnosed in cows with internal pathology. Namely, in blood serum of cows suffering from osteodystrophy, the glucose content was lower by $13 \%$, and in case of ketosis and hepatodistrophy - by $29.6 \%(\mathrm{P}<0.001)$ and $22.7 \%$ $(\mathrm{P}<0.05)$, respectively, compared with clinically healthy animals. The lowest levels of glucose in serum were recorded in cows suffering from ketosis.

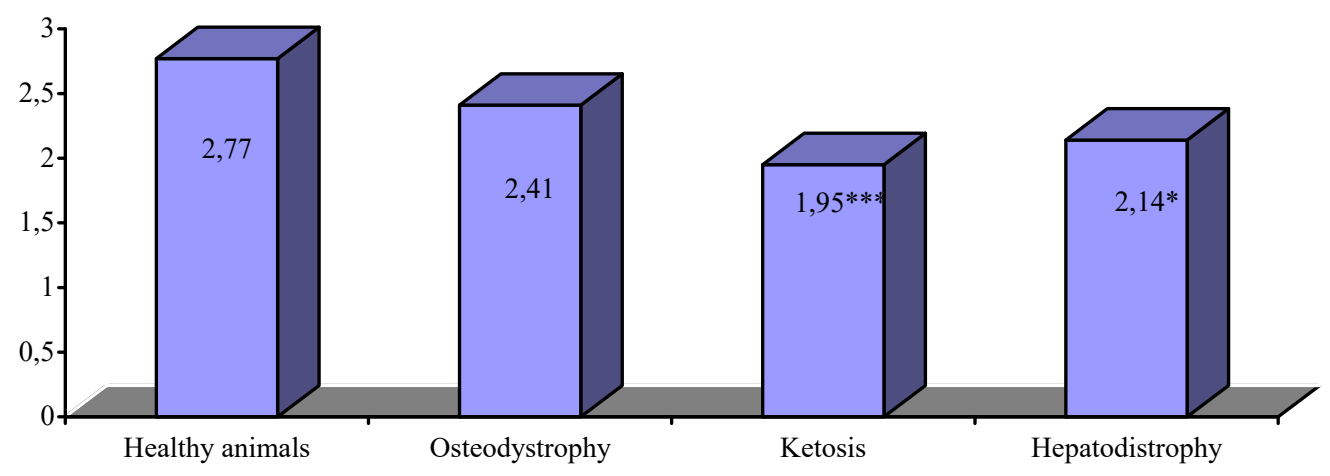

Fig. 1. Glucose content in blood serum of cows (mmol/l)

The direction of glucose metabolism can be judged by the level of pyruvate and lactate in the blood. The studies conducted by us showed the highest content of pyruvate in the blood of cows suffering from ketosis. Thus, in comparison with the group of clinically healthy cows, it was twice as high $(\mathrm{P}<0.01 ;$ tab.). In osteodystrophy and hepatodystrophy, compared to a group of clinically healthy cows, the pyruvate content was higher by 28.6 and $39 \%(\mathrm{P}<0.01)$, respectively.

\section{Table 1}

The content of pyruvate and lactate in blood serum of cows $(\mu \mathrm{mol} / \mathrm{L}, \mathrm{mmol} / \mathrm{l})$

\begin{tabular}{ccccc}
\hline \multirow{2}{*}{ Indicators } & \multirow{2}{*}{ Healthy animals } & \multicolumn{3}{c}{ Ill animals: } \\
\cline { 3 - 5 } & & Osteodystrophy & Ketosis & Hepatodistrophy \\
\hline Pyruvate $\mu \mathrm{mol} / 1$ & $133.3 \pm 12.68$ & $171.4 \pm 11.20$ & $257.1 \pm 21.65^{* *}$ & $185.4 \pm 6.32^{* *}$ \\
Lactate $\mathrm{mmol} / \mathrm{l}$ & $1.9 \pm 0.44$ & $2.6 \pm 0.36$ & $4.2 \pm 0.43^{*}$ & $3.5 \pm 0.33^{*}$ \\
\hline
\end{tabular}

Note: statistically probable difference compared to healthy cows: $* *-\mathrm{P}<0.01 ; *-\mathrm{P}<0.05$ 
When comparing the content of lactate in healthy and ill cows, higher rates were established. Namely, for osteodystrophy - by $36.8 \%$, hepatodistrophy - by 1.8 times $(\mathrm{P}<0.05)$, and for ketosis - by 2.2 times $(\mathrm{P}<0.05)$. Ketosis of dairy cows and osteodystrophy often overlap with the pathology of the liver. The growth of the content of pyruvate and lactate on the one hand may be due to liver damage, where the main stages of their metabolism pass, and on the other - by activation of gluconeogenesis. The liver is the main organ that provides a constant concentration of glucose in the blood due to the processes of synthesis and disintegration of glycogen and glycogenogenesis, that is, it performs hemostatic function. Violation of glycogen synthesized liver function, i.e. its ability to create metabolic glycogen reserves and their use as an energy material for the functioning of other organs, indicates a decrease in the ability of hepatocytes to synthesize glycogen from glucose. By activating ATP, glucose is first converted to glucose-6-phosphate, and then into glucose-1-phosphate and uradidine phosphate glucose, which attaches the glucose residue to the glycogen molecules, and the synthesis of glucose from noncarbohydrate metabolites. For liver damage, the level of oxidative processes in hepatocytes decreases, which leads to a decrease in activity of glycogenesis and, as a consequence, a violation of the involvement of the liver in the regulation of blood glucose levels.

According to the study of insulin-like growth factor, the lowest level was found in the group of cows suffering from ketosis, and the highest - in clinically healthy (Fig. 2). Thus, in plasma of cows blood suffering from osteodystrophy, in comparison with clinically healthy, the concentration of IFI was lower by $7.3 \%$, for hepatodystrophy - by $17 \%$ $(\mathrm{P}<0.05)$, and for ketosis - by 28.2\% $(\mathrm{P}<0.001)$.

The decrease in the concentration of IUF in the blood of diseased cows is apparently due to hypoglycemia, which occurs with a decrease in the concentration of insulin. It is known that insulin concentration is significantly reduced with a negative energy balance (Vlizlo et al., 2018).

The dynamics of changes in the concentration of leptin in the blood plasma of ill cows was similar to that of an IFI (Fig. 3). In particular, the content of leptin in blood plasma of patients with osteodystrophy of cows was lower by $11.4 \%$, for ketosis and hepatodistrophy by $45.1 \%$ $(\mathrm{P}<0.001)$ and $39.7 \%(\mathrm{P}<0.01)$, respectively.

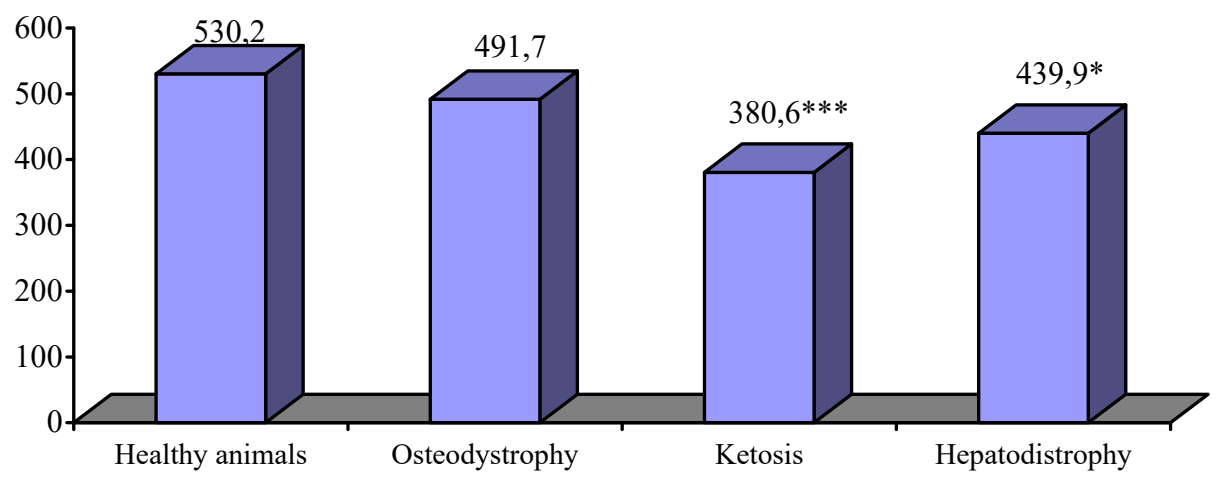

Fig. 2. Content of IFI-1 in blood plasma of cows (mmol/1)

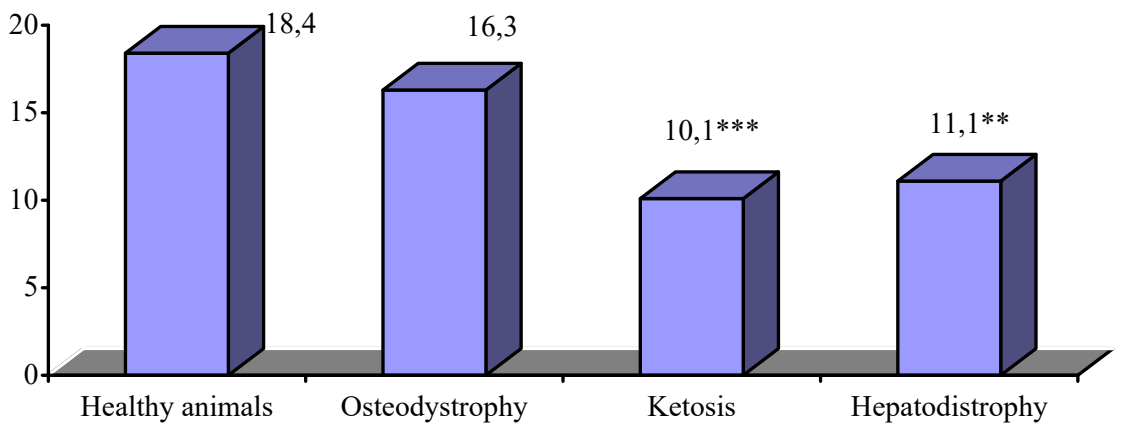

Fig. 3. The content of leptin inblood plasma of studied cows ( $\mathrm{mmol} / \mathrm{l})$

Since leptin is directly involved in energy metabolism and is responsible for the sense of satiety and appetite, lowering its level in the blood of diseased cows may indicate a disturbance in their appetite, a change in the metabolism of fats with high energy expenditure.

\section{Conclusions}

1. In the internal non-contagious pathology of dairy cows, a deficiency of exchange energy is recorded, which induces an increase in the activity of gluconeogenesis and is expressed by lowering the concentration of glucose and increasing the content of pyruvate and lactate.
2. The established decrease in the level of IFIs and leptin is associated with the change in metabolic rates confirms the existing data on the ability of IFI-1 to regulate metabolic processes, showing endocrine, parathyroid and cranial effects.

\section{References}

Vlizlo, V., \& Simonov, M. (2017). Concentration of Insuline-Like Growth Factor and Leptin in plasma of dry and early lactation dairy cows. XVII. Middle European Buiatrics Congress (Strbske Pleso - High Tatras, Slovakia), 90-94. 
Vlizlo, V., Petruh, I., Simonov, M., \& Slivinska, L. (2018). Hormonal regulation of energy metabolism in ketotic cows. XVIII. Middle-European Buiatrics Congress (Eger, Hungary), 294298.

Kim, J.W. (2014). Modulation of the somatotropic axis in periparturient dairy cows. Asian-Australas J. Anim. Sci, 27(1), 147-54. doi: 10.5713/ajas.2013.13139.

Vlizlo, V., Fedoruk, R., Ratych, I., ta in. (2012). Laboratorni metody doslidzhen u biolohii, tvarynnytstvi ta veterynarnii medytsyni: dovidnyk. Lviv, SPOLOM (in Ukrainian).

Levchenko, V.I., Kondrakhin, I.P., ta in. (2015) Vnutrishni khvoroby tvaryn. Bila Tserkva (in Ukrainian).

Montague, C.T., Farooqi, I.S., Whitehead, J.P., Soos, M.A., Rau, H., Wareham, N.J., et al. (1997). Congenital leptin deficiency is associated with severe early-onset obesity in humans. Nature 387(6636), 903-908. doi: 10.1038/43185.

Nikolic-Judith, A., Samanch, H., \& Kovacevich, M. (2001). Serum concentrations of insulin-like growth factors and thyroid hormones in healthy and ketotic dairy cows during the puerperium. Acta Veterinaria, 51(2-3), 73-88. doi: 10.2298/AVB1106489P.

Partridge, L., Alic, N., \& Bjedov, I. (2011). Ageing in drosophila: the role of the insulin/Igf and TOR signalling network. J. Exp Gerontol, 46(5), 376-81. doi:10.1016/j.exger.2010.09.003.

Cerrilla, E.O., \& Martínez, G.M. (2003). Starch digestion and glucose metabolizm in the ruminant: a review. J. Anim. Sci, 71, 18-25. http://fliphtml5.com/mxaj/deoa/basic. 